\title{
Analysis of Changes of Forces and Normal Stress in Extradosed Tendons of the MS-3B Bridge Located on the Ring Road in Ostróda
}

\author{
Tadeusz Stefanowski ${ }^{2}$, Piotr Supet ${ }^{1}$, and Wojciech Trochymiak ${ }^{1, *}$ \\ ${ }^{1}$ WUT, The Faculty of Civil Engineering, Institute of Roads and Bridges, 00-637 Warsaw, Poland \\ ${ }^{2}$ ZUP "Mostex" Tadeusz Stefanowski, 83-300 Kartuzy, Poland
}

\begin{abstract}
The article discusses the analyses of a numerical model of an extradosed bridge built as part of the project called "Construction of S7 expressway connecting Miłomłyn and Olsztynek, together with construction of Ostróda Bypass as a section of national road no. 16." The constructed facility fits in with the global trends of construction of next generation concrete bridges with tensioned tendons. The bridge is the best in its class in Europe in terms of the length of its main span. It is also one of the first concrete bridges in Poland which have been built using cantilever technology in which the extradosed tendons were stressed during construction process. The article contains, in particular, the selected results of the analyses related to changes of forces and normal stresses in extradosed tendons depending on live loads to which the bridge was exposed during the service phases, while accounting for environmental and rheological as well as passage of time.
\end{abstract}

\section{Introduction}

Extradosed bridges (ex-d for short) are among the latest trends in the development of the bridges made of posttensioned concrete (in the classical Mathivata approach [1]) that are characterized by innovative structural and technological solutions. Extradosed bridges include the structures which have the features proposed by Mathivat as well as the structures with parameters which are characteristic for cable-stayed bridges with low pylons, or the bridges with tendons covered with above girder.

Depending on the rigidity of girders and cable stays in cable-stayed bridges or tendons/cables extradosed in extradosed bridges, a bridge can be designed with a factor of safety for ex-d tendons/cables ranging from 1.67 (due to tensile stress in the tendons being restricted to range of $0.6 f_{p k}$ ) to 2,5 (restriction of tensile stress to $0.4 f_{p k}$ ). The factor of safety which can be adopted for ex-d tendons/cables depends on the conditions in which a tendon operates [2]. Extradosed bridges with concrete girders which were built around

\footnotetext{
* Corresponding author: w.trochymiak@il.pw.edu.pl
} 
world have spans of up to 250 meters and bridges with spans reaching 280 meters are being designed and built.

One of the latest, interesting structural solutions in the construction of bridges with prefabricated butterfly web which enables construction of extradosed bridges with spans of up to 500 meters and cable-stayed bridges with spans reaching 800 meters [3]. The MS-3B bridge located along the ring road around Ostróda [4] follows global trends in the construction of ex-d bridges.

\section{Description of the bridge}

MS-3B bridge is located along the national route no. 16 on Ostróda ring road, at 14+065.37 kilometer in Warmińsko-Mazurskie province in Ostróda county. The superstructure of the facility is a four-span, three-chamber box girder which is pre-stressed with the use of internal and external tendons, installed inside the girder box, and with ex-d tendons. The total length of the girder is $680 \mathrm{~m}$ (Figure $1 \div 4$ ).

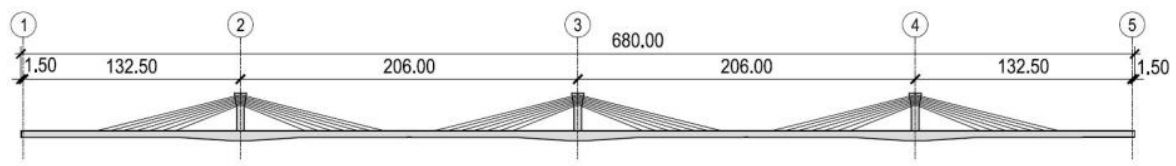

Fig. 1. Diagram of the bridge - spans

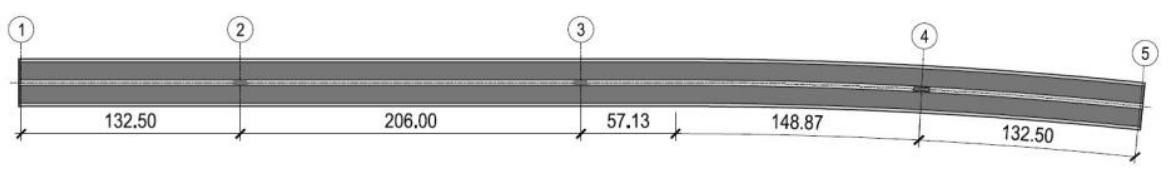

Fig. 2. Diagram of the bridge - top view

The structural height of a girder varies within $4 \div 6$ meter range. The top slab has a permanent width of $28.40 \mathrm{~m}$ and thickness varying in the range $27.5 \div 60.0 \mathrm{~cm}$. The bottom slab has varying width, in the range $13.00 \div 9.93$ meters, and varying thickness of $25.0 \div 105.0 \mathrm{~cm}$. Cross bars (struts) are installed every 8 meters on average.

Tensioning of the girder in the longitudinal direction has been achieved by using internal bonded tendons (22L15.7 and 12L15.7, in both the upper and the lower slab); external unbonded tendons (37L15,7 in HDPE casings inside the box cross-section, and ex$\mathrm{d}$ tendons (with a variable number of splices, in a single plane above the deck).

Tensioning of angle struts in the transverse direction (22L15.7 in the places where the ex-d tendons are anchored and on the bottom slab, in the location of the supports) as well as of the upper slab of the deck with internal bonded tendons (3x1L15.7, spaced every $0.40 \mathrm{~m}$ on the average). Also vertical tensioning of pylon no. 4 (22L15.7) was designed, along with temporary additional tensioning of the girder to the supports during the construction process.

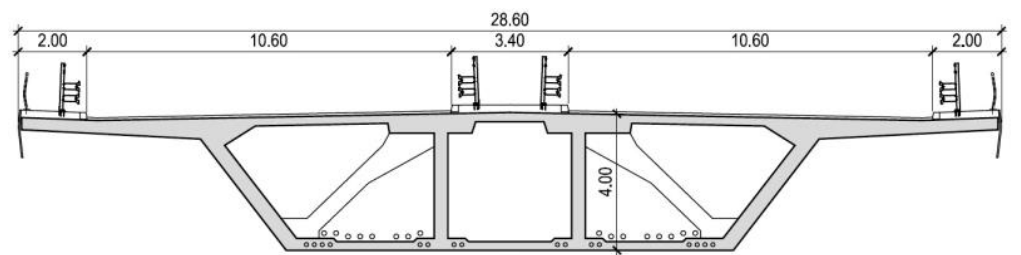

Fig. 3. Cross-section of the girder - span-type 
The ex-d tendons are situated in one plane, symmetrically, 7 each on either side of the pylon, and they consist respectively of 167,139 or 135 seven-wire strands with the diameter of $15.7 \mathrm{~mm}$ (from the longest to the shortest). Ex-d tendons are anchored to the pylon by means of passive anchoring (saddle) and to the girder, to the anchoring blocks (active anchoring). The longest ex-d tendon, having the length of $185.6 \mathrm{~m}$, is inclined at $14.5^{\circ}$ with regard to the girder. The length of the shortest ex-d tendon is $90.6 \mathrm{~m}$ (with the angle of inclination of $22.8^{\circ}$ ).

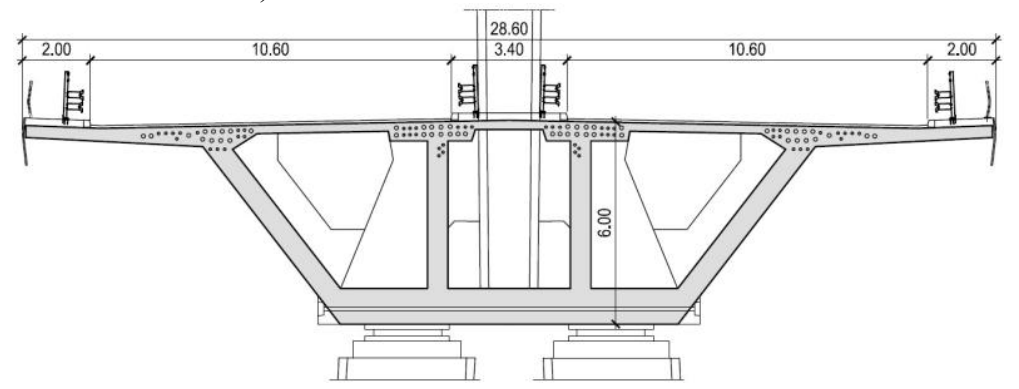

Fig. 4. Cross-section of a girder - support-type

The pylons, which are restrained in the girder's cross-section, are located above the intermediate supports and in the center-line of the cross-section. The height of the pylons is 23 meters above the deck. The width of the pylons no. 2 and 3 varies from $.00 \div 7.50 \mathrm{~m}$, while the width of the pylon above the support no. 4 changes in the range $6.00 \div 9.50 \mathrm{~m}$. The thickness of the pylons varies in $1.80 \div 2.30 \mathrm{~m}$ range. The facility has been designed as load class A, as defined by PN-S-10030:1985 norm and military loads (STANAG 150, MLC 150 and $2 \times$ MLC 100) defined according to relevant regulations.

\section{Adopted assumptions}

The geometry of the structure, the layout and the parameters of installation routes of tensioning tendons as well as the method of construction have been all adopted on the basis of the documentation. Construction of the superstructure by means of cantilever method required that the girder had to be constructed in segments. The facility was divided into 3 main installation sections (cantilever arms): supports 2, 3, 4) and into installation segments (Figure 5), including:

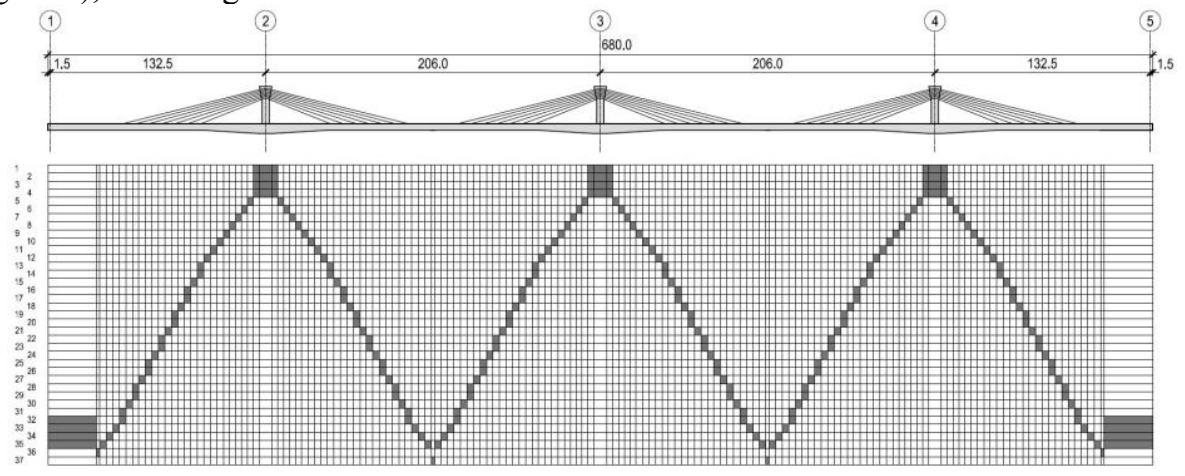

Fig. 5. The facility's construction schedule adopted for analysis; closing segments $Z 1 \div Z 4$ have been marked accordingly in the following way: Z1-span 1-2; Z2-span 2-3; Z3- span 3-4; Z4-span 4-5.

- start segments with the length of $15.2 \mathrm{~m}$ and variable height,

- segments with the length of $3.6 \mathrm{~m}$ and variable height, 
- segments with the length of $4.0 \mathrm{~m}$ and variable height,

- $\quad$ segments with the length of $4.0 \mathrm{~m}$ and fixed height $(4.0 \mathrm{~m})$,

- extreme segments with the length of $30.0 \mathrm{~m}$ and fixed height $4.0 \mathrm{~m}$,

- closing segments with the length of $2.0 \mathrm{~m}$ and height of $4.0 \mathrm{~m}$.

30-meter long fragments of the girder, on fixed scaffolding, are planned to be constructed in the direct vicinity of the abutments. Three pairs of travelers have been used for constructing the superstructure, which enabled simultaneous construction of the superstructure from each starting section. Temporary supports have been planned by each pillar during the process of construction of the superstructure so as stabilize the uneven shift of the supports.

\section{The analyzed model}

The calculation model (Figure $6 \div 7$ ) has been developed with the use of SOFiSTiK software while adopting the following assumptions in particular:

- models of the materials: concrete C60/75 (acc. to PN-EN 206-1), having the gravity of $27 \mathrm{kN} / \mathrm{m}^{3}$ (the value of $26.5 \mathrm{kN} / \mathrm{m}^{3}$ has been adopted while developing the Construction Design (PB) and the Technical Design (PT)) and Young's module of $55.5 \mathrm{GPa}$; tensioning steel - tensioning tendons and ex-d tendons - with the nominal tensile strength of $1860 \mathrm{MPa}$ and Young's module of $195 \mathrm{GPa}$, diameter of the strands $-15.7 \mathrm{~mm}\left(150 \mathrm{~mm}^{2}\right)$,

- cross-sections of the girder: 12 different cross-sections have been adopted; crosssections with varied height have been modeled by way of linear interpolation of parametrized cross-sections,

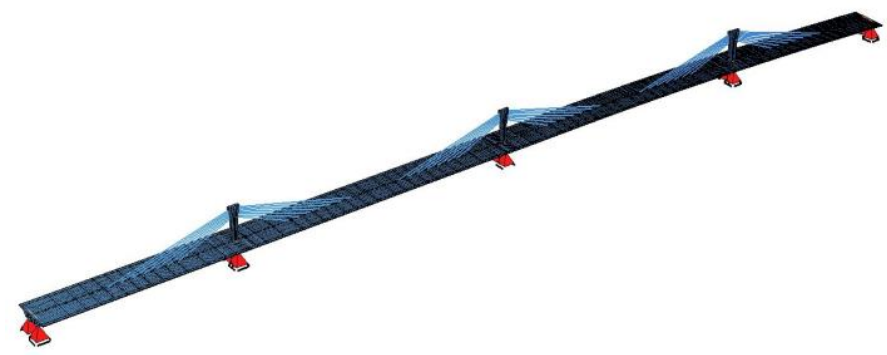

Fig. 6. Visualization of the model of a beam [5]

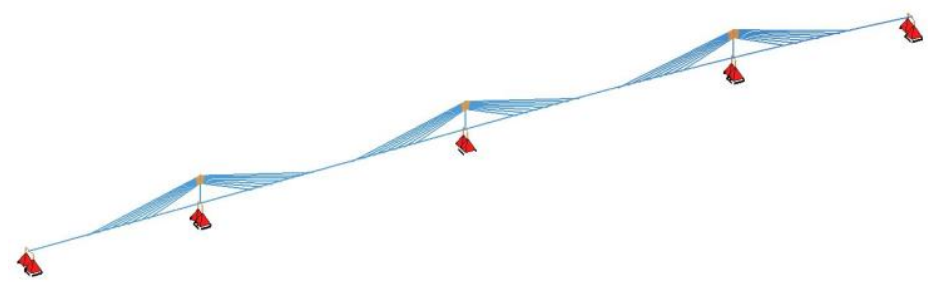

Fig. 7. Diagram of the model of a beam [5]

- cross-sections of the pylons: variable width has been taken into account- relevant parametrization of the cross-section has been performed while using the available functions of the software,

- modeling of the tensioning (Figure 8): internal tendons with bonding and without bonding -the installation route of the tendons has been modeled with regard to the 
center-line of the facility by locating the tendons accordingly in the cross section and along the length of the facility; the tendons ( 472 pcs.) were divided into 42 groups, depending on the type, the number of strands and construction work phase,

- modeling of tensioning: ex-d tendons (Figure 6 $\div 7$ ) - defined as cable-type elements with a circular surface (cross-section) area which is equal to the summary area of the surface of the strands (the numbers of strands: 135/139/167 - the area of tensioning steel $\left[\mathrm{m}^{2}\right]$-respectively $\left.0.0203 / 0.0210 / 0.0251\right)$,

a)

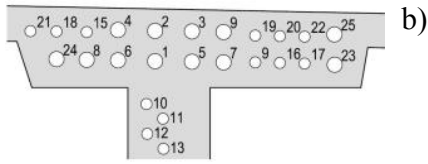

c)

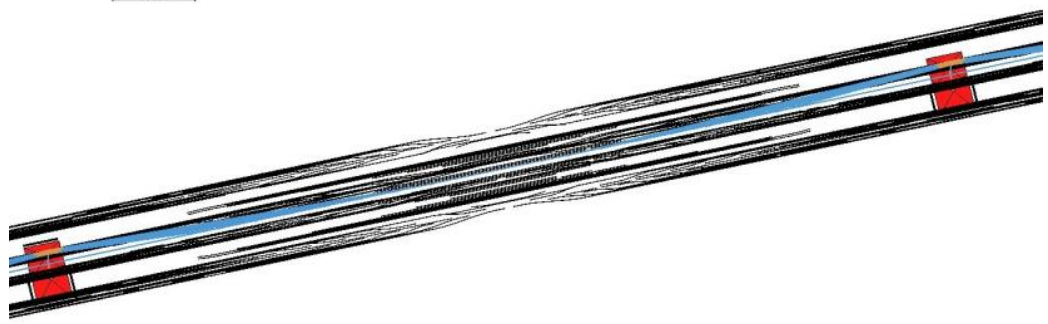

Fig. 8. Layout of tensioning tendons: a)-b) the numbering of internal tendons with bonding above the vertical web (a), above the skewed web (b); c) visualization of a span's tensioning system - fragment

- tensioning of tendons - the forces used to tension the tendons, except the ex-d tendons have been modeled in such a way that following occurrence of immediate loss the tensile stress in the tendon should not exceed $0.65 f_{p k}$ or $0.75 f_{p k}$, respectively for internal tendons with bonding or external tendons without bonding; the tensioning forces in ex-tendons were modelled in three stages depending on the location of the tendons - the initial forces were adopted in the $0.30 \div 0.40 F_{p k}$ - as further parts of the girder were added, single tensioning of the girder (before installing the closing segment), or double tensioning for part of ex-d tendons (before installing the fixtures) were planned,

- usable states, accounting for the influence of time, were analyzed in the elastic range while accounting for PN-S-10030:1985 and PN-S-10042:1991 norms,

- models of the material, accounting for the changes of their properties with time, especially change of the concrete elasticity modulus [5], for which the function of change in time (CEM $42.5 \mathrm{R}$ and the value of the factor $\mathrm{s}=0.25$ were adopted),

- change of the values of the forces and the tension was analyzed over a longer timeframe - 20 years while developing the Construction Design/the Technical Design, 80 years for analytical purposes $(t=\infty)$.

\section{Examples of selected results}

The usable phase was analyzed while accounting for the construction of the facility with the use of the cantilever method. Static analysis of the facility was performed upon completion of the construction, once the target static diagram has been reached. The influence that the variable parameters of the modeled tensioning (internal tendons with bonding and external tendons without bonding located inside the girder's cross-section, extradosed cables) have on internal forces, displacement and stress in the girder and in the ex-d tendons were examined. 
The influence that thermal and rheological factors have on redistribution of normal stress in the extreme fibers of a girder as well as in the tensioning tendons was included. Particular attention ws drawn to examination of the impact that operational loads have on the scope of change of internal forces and normal tensile stress $(\Delta \sigma)$ in extradosed tendons.

Figures $9 \div 14$ illustrate the selected results of the analyses. Figure 9 contains the graph of summary normal forces. Fig. 10 presents the graphs of the envelope of normal stress in the extreme fibers of a tendon after 80 years (the Serviceability Limit State - SLS).

All the analyzed cross-sections meet the requirements of PN-S (polish standard - design compressive strength of 46,2 $\mathrm{MPa}$, characteristic tensile strength of 3.1 MPa). In the course of development the Construction Design (PB) and the Implementation Design (PW), the normal compressive strength in the extreme fibers of the girder (in a non-operational state) were within $12 \div 32 \mathrm{MPa}$ range in the extreme spans (depending on their cross-section area) and respectively within $23 \div 38 \mathrm{MPa}$ range in the main span (206m long).

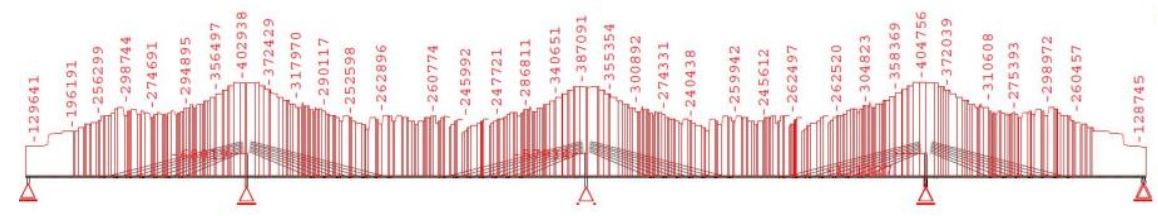

Fig. 9. Graph showing normal forces (summary) in a girder resulting from stressing ( $\mathrm{t}=1$. year)

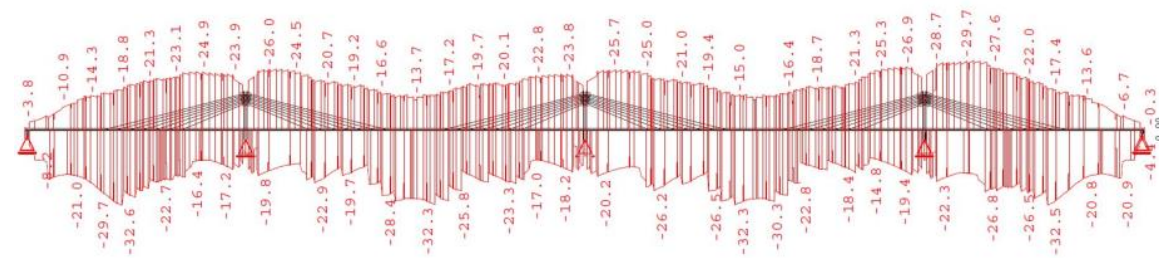

Fig. 10. Graph presenting envelope of normal stress in a girder ( $S G U$ - limit state) $(t=80$. years)

Figures $11 \div 12$ contain the comparison of the extreme values of normal tensile stress in ex-d tendons generated by all examined loads and reactions in a year's time after putting the bridge into operation (Figure 11) as well as after 80 years of operation (Figure 12). Extreme values of normal stress in ex-d tendons are within the $(0.4 \div 0.6) f_{p k}$ range. Maximum values of normal stress are seen in the longest ex-d cables in the extreme spans where they reach values of up to $1030 \mathrm{MPa}$ after the first year and up to $990 \mathrm{MPa}$ after 80 years.

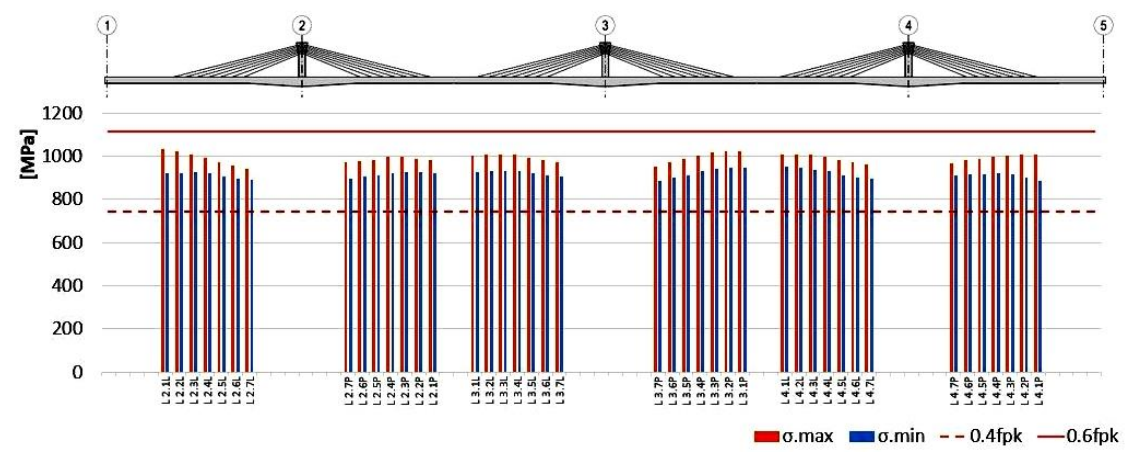

Fig. 11. Graph presenting extreme values of normal stress in ex-d cables $\left(t=1^{\text {st }}\right.$ year $)$ 
Figure 13 contains graphs illustrating changes of normal stress $(\Delta \sigma)$. Changes of tensile stress, caused by operational loads, range from $55 \mathrm{MPa}$ (the shortest cables) to $120 \mathrm{MPa}$ (the longest cables in the extreme spans).

Figure 14 illustrates the extreme, vertical displacement of the girder resulting from operational loads after one year since putting the facility into operation. The extreme vertical displacements of the206-meter span are $\sim 260 \mathrm{~mm}$ after the first year (respectively $254 \mathrm{~mm}$ after 80 years), which is equal to around $1 / 800^{\text {th }}$ part of the length of a span $(257.5$ $\mathrm{mm}$ ). In the course of development of the Construction Design (PB) and the Implementation Design (PW), the design deflection ranged from $115 \mathrm{~mm}$ in the extreme spans to around $289 \mathrm{~mm}$ in the central spans, however while accounting for the lower value of the Young's module for concrete.

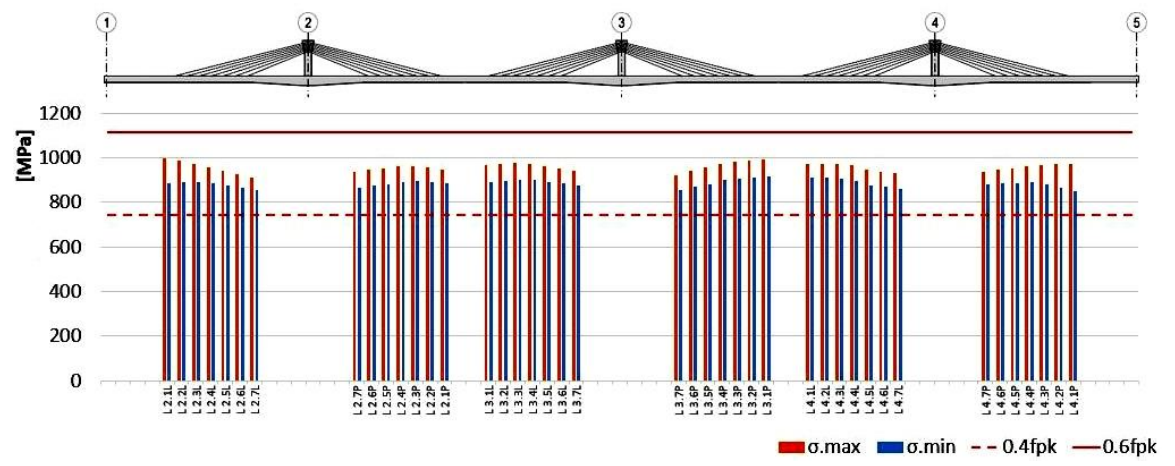

Fig. 12. Graph presenting the extreme values of normal stress in ex- $\mathrm{d}$ cables ( $\mathrm{t}=80$ years)

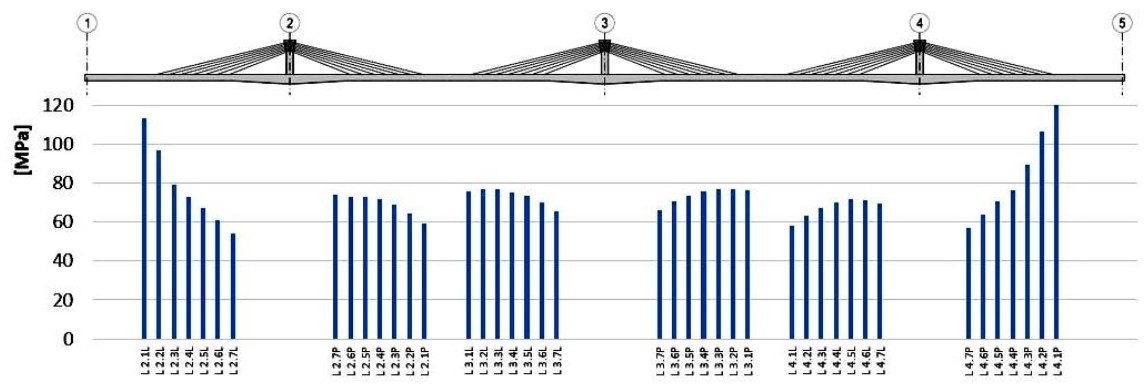

Fig. 13. Graph presenting changes of normal stress in ex-d cables as a result of live loads ( $t=1 \mathrm{y}$.)

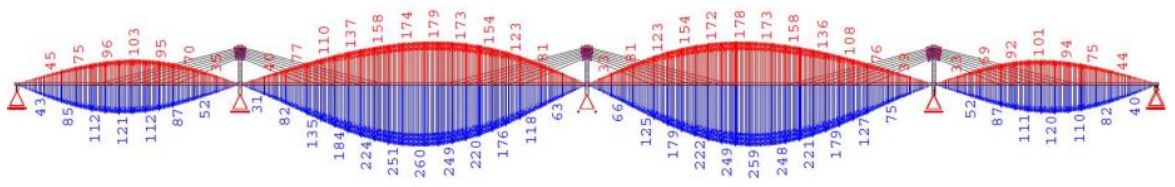

Fig. 14. Graph presenting the vertical displacement of a girder as a result of live loads ( $t=1 \mathrm{y}$.) [mm]

\section{Final conclusions}

Operational states of the facility were analyzed while using the class $e^{l}, p^{3}$ beam model which accounts for respective phases of the construction process. The analysis included in particular the internal forces (the bending moment, the lateral (shearing) forces, the longitudinal forces), response in the supporting nodes, normal stress in extreme fibers of a 
girder, shear stress, vertical displacement of the girder, normal stress (force) in extradosed cables, range of normal stress changes in extradosed tendons due to live loads while accounting for the combination of long-lasting and operational loads as well as for rheological influence. Only selected results have been quoted due to the limited scope of the paper.

According to [6] the category of ex-d tendons should include all the external tendons situation above or under the girder that were earlier categorized as external tendons with large eccentricities. Thus there emerge various proposals that qualification of tendons in structures should be based on several criteria (Table 1) and that the suspension cables or ex$\mathrm{d}$ tendons be selected on case-by-case basis, depending on operating conditions.

Table 1. Selected criteria of classification of tendons (suspension cables) [6]

\begin{tabular}{|c|c|c|c|}
\hline Specification & $\begin{array}{c}\text { Suspension } \\
\text { cables }\end{array}$ & $\begin{array}{c}\text { Extradosed } \\
\text { tendons }\end{array}$ & External tendons \\
\hline Situation of a tendon & $\begin{array}{c}\text { Below the } \\
\text { girder }\end{array}$ & $\begin{array}{c}\text { Above or below } \\
\text { the girder }\end{array}$ & $\begin{array}{c}\text { Within the limits of a } \\
\text { girder's construction } \\
\text { height }\end{array}$ \\
\hline $\begin{array}{c}\text { Ratio of variable loads carried } \\
\text { by tendons (cables) }\end{array}$ & $(40 \div 90) \%$ & $(10 \div 50) \%$ & $(0 \div 50) \%$ \\
\hline $\begin{array}{c}\text { Range of stress caused by } \\
\text { variable loads }\end{array}$ & $\begin{array}{c}(100 \div 200) \\
\mathrm{MPa}\end{array}$ & $(20 \div 120) \mathrm{MPa}$ & $(0 \div 50) \mathrm{MPa}$ \\
\hline $\begin{array}{c}\text { Effective level of stress in } \\
\text { tendons (cables) })\end{array}$ & $45 \% f_{p k}$ & $(60 \div 65) \% f_{p k}$ & $(75 \div 80) \% f_{p k}$ \\
\hline
\end{tabular}

$\left.{ }^{*}\right)$ The level of tensile stress in tendons (cables) is taken as the reference point when developing a design, it is compared to the load capacity at the moment of breaking $f_{p k}$

While concluding, it can be said that:

- MS-3B on Ostróda bypass fits in with the global trends of construction of next generation concrete bridges with tensioned tendons - the extradosed bridges,

- the parameters which have been analyzed and verified, especially the ones pertaining to normal stress in the girder and in the tensioning tendons, including the ex-d tendons, or the vertical displacement of the girder due operating loads, meet the requirements of relevant regulations,

- the values of tensile stress changes $(\Delta \sigma)$ in ex-d tendons, caused by operational loads, range between 55 and $120 \mathrm{MPa}$ and meet the guidelines detailed in Table 1 above.

\section{References}

1. J. Mathivat, FIP Notes, 2 (1998)

2. W. Trochymiak, Inżynieria i Budownictwo, 10 (2014)

3. A. Kasuga, Multi-span extradosed bridges, Multi-Span Large Bridges-Pacheco \& Magalhăes (Eds.), 67-82 (Taylor \& Francis Group, London, 2015)

4. T. Stefanowski, MS-3 Bridge on Ostróda Bypass - a designer's view, Mosty 5 Elamed Media Group (2017)

5. P. Supeł, W. Trochymiak, Scientific and Technical Seminar. Evolution of design and construction technologies, DWE (2017)

6. W. Brandt, Scientific and Technical Seminar. Technology in construction (2010) 